\title{
El papel de la publicidad social en el abordaje de la vulnerabilidad sociocultural. Panorama y reflexiones a propósito del caso español ${ }^{1}$
}

\section{Jorge Grau Rebollo}

Doutor; Universitat Autònoma de Barcelona. Bellaterra (Cerdanyola del Vallès, Barcelona), Espanha. jordi.grau@uab.cat

\section{Resumen}

El objetivo de este artículo es reflexionar, a partir de la revisión de literatura internacional relevante sobre el tema, acerca del papel que los medios de comunicación y la publicidad social pueden jugar en la cobertura y tratamiento de situaciones de vulnerabilidad sociocultural, con especial atención al caso español, uno de los países europeos más castigados por la crisis global desatada en Estados Unidos en el año 2008. Fruto de esta revisión de discursos expertos, se sintetizan: (1) algunos niveles que frecuentemente aparecen como nodos centrales de la conexión entre publicidad y vulnerabilidad; (2) la delimitación de colectivos y agrupaciones particularmente susceptibles, por su condición de vulnerados/as, de convertirse en objeto de representación; y (3) algunos ámbitos de confluencia habituales en el encuadre del problema. A continuación, se dirige la atención a las estrategias narrativas en la elaboración de campañas de sensibilización sobre pobreza y vulnerabilidad, combinando información estadística con la relevancia de las formas de representar a los sujetos vulnerados, y recurriendo a dos ejemplos concretos de spots publicitarios elaborados en el seno de este tipo de campañas en España. Entre las conclusiones más relevantes del texto, destacan las recurrencias representacionales de ciertos colectivos y agrupaciones, la importancia de trabajar con un lenguaje audiovisual muy cuidado, la preferencia por centrar la atención narrativa en situaciones de alto impacto emocional, o el potencial transformador que puede encerrar el medio publicitario en entornos de vulnerabilidad social. Por último, se definen ámbitos relevantes para abordar en futuros estadios de investigación.

\footnotetext{
${ }^{1}$ Este artículo es resultado del trabajo que llevo a cabo en el seno del proyecto de investigación en curso Crianza, desamparo y vulnerabilidad sociocultural. Análisis situacional y propuestas de intervención (Referencia CSO2017-83101-C2-1-R), financiado por el Ministerio de Economía, Industria y competitividad y dirigido por Jorge Grau Rebollo y Anna Piella Vila.
} 


\section{Palabras clave}

Publicidad. Vulnerabilidad social. Estrategias narrativas. España.

Lenguaje audiovisual.

\section{Introducción}

La profunda crisis financiera que se desencadenó en 2008 ha conducido en diversos países, a un incremento en el número de hogares en situación de riesgo o de pobreza. En el caso español, la tasa de pobreza se ha mantenido durante los años de la crisis en torno al 18\% - 19\%, nivel sensiblemente más alto que el de otros países de su entorno geopolítico (TEZANOS et al., 2013), llegando a situarse el riesgo de pobreza o exclusión en un 29,2\% según la Encuesta de Calidad de Vida correspondiente a 2014 (INE, 2016). Esta pauperización social ha creado una dinámica de fragilidades convergentes que ha comportado, entre otras cosas, la pérdida de puestos de trabajo y la mengua de ingresos en muchos hogares, al tiempo que los servicios asistenciales se han contraído y la provisión de recursos públicos destinados a paliar situaciones carenciales moderadas y severas ha disminuido considerablemente. Todo ello ha alentado a una amplia movilización del tejido asociativo (singularmente el llamado tercer sector), además de una amplia atención académica y profesional sobre el fenómeno.

En esta línea, desde la academia han proliferado estudios que han abordado el fenómeno desde perspectivas distintas y al amparo de diferentes disciplinas, entre las que se cuentan: (1) la Antropología Social y Cultural (por ejemplo, MESTRES et al., 2012; RIVAS; JOCILES, 2009); (2) la Ciencia Política (NAVARRO; CLUA-LOSADA; TUR, 2012; SARASA; LUPPI, 2012); (3) la Economía (CARRASCO; BORDERÍAS; TORNS, 2011; SEN; BRUNDTLAND, 1999); (4) la Geografía Social y Humana (SÁNCHEZ-GONZÁLEZ; EGEA-JIMÉNEZ, 2011); (5) la Pedagogía (FUENTES-PELÁEZ et al., 2014; SÁNCHEZ; SANDÍN, 2013); (6) la Medicina (RODES LLORET; MONERA OLMOS; PASTOR BRAVO, 2011); (7) la Psicología (SCHRAG; SCHMIDT-TIESZEN, 2014); (8) la Sociología (DIMAGGIO; GARIP, 2012; MEIL, 2011; TEZANOS et al., 2013) o (9) el Trabajo Social (LAPARRA; PÉREZ ERANSUS; LASHERAS RUIZ, 2012; MATÍAS-SOLANILLA, 2015).

Desde el ámbito específico de la comunicación destacan las aportaciones recogidas en La infancia vulnerable en los medios de comunicación (MANRIQUE, 2015) a propósito de informaciones aparecidas en la prensa española sobre vulnerabilidad -específicamente infantil-, Arely Donis y Martín Casado (2017), quienes llevan a cabo un análisis de 
contenido sobre una muestra de publicidad social gráfica de ONGD publicada en redes sociales en España entre 2011 y 2016, o la propuesta de Lara (2008) en el sentido de considerar la comunicación como una herramienta de gran valor estratégico para el tercer sector no lucrativo. En esta línea, algunos estudios han hecho hincapié en la incidencia política de las campañas (SAIZ-ECHEZARRETA; ALVARADO; GÓMEZ-LORENZINI, 2018) y la importancia de éstas en el tratamiento de la inclusión social (ALVARADO LÓPEZ, 2009; ALVARADO LÓPEZ; ANDRÉS DEL CAMPO; COLLADO ALONSO, 2017). Así, en el plano mediático y publicitario queda patente la potencialidad de orientar una intervención social transformadora apoyándose en la publicidad como herramienta de cambio, más allá de su condición estrictamente comunicativa.

En esta línea, propongo aquí una reflexión sobre el papel que los medios de comunicación y la publicidad pueden jugar en la cobertura y tratamiento de las situaciones de vulnerabilidad a partir de literatura internacional relevante sobre el tema y con especial atención al caso español, uno de los países europeos más castigados por la crisis (LAPARRA et al., 2012). El marco referencial inmediato se sitúa en el proyecto de investigación Crianza desamparo y vulnerabilidad sociocultural (CSO2017-83101-C2-1-R), que contempla, entre otros objetivos, el análisis del rol (o roles) que desempeñan los medios audiovisuales y las campañas publicitarias en el abordaje y paliación de la vulnerabilidad social en ámbitos especialmente frágiles, como los vinculados a situaciones de crianza de niños y niñas.

Debo matizar, respecto al párrafo anterior, un par de cuestiones. En primer lugar, restringiré la vulnerabilidad a su condición sociocultural, descartando otras tipologías (e.g. consecuencia directa de catástrofes ambientales, sanitarias, humanitarias -como por ejemplo conflictos armados-, o exposición general a este tipo de acontecimientos). En segundo lugar, no me referiré a la publicidad en su conjunto, puesto que sería un propósito inabarcable en el contexto restringido de un único artículo, sino que me circunscribiré a la publicidad no comercial, considerada también cívica o de bien público, siguiendo la definición de Méndez (2009) y que subraya como elementos esenciales a tener en consideración su carácter altruista y su propósito movilizador:

Se llaman así las campañas realizadas por entidades sin ánimo de lucro o por empresas que se colocan en un papel similar. Con frecuencia los gobiernos, fabricantes o entidades de servicio a la comunidad o caritativas, $\mathrm{u}$ otras asociaciones, buscan cambiar actitudes masivas mediante la oferta de satisfactores diferentes a un producto rentable: cultura, turismo, rehabilitación de minusválidos, patriotismo. Sus fines son altruistas, invitan a obrar, a congregarse alrededor de causas importantes para conglomerados sociales: combatir la droga, fomentar los cuidados ecológicos, etc. [...]". (MÉNDEZ, 2009, p. 2,). 


\section{En torno a la noción de vulnerabilidad sociocultural.}

Desde una perspectiva semántica La Real Academia Española de la lengua define genéricamente vulnerabilidad como la "cualidad de vulnerable" entendiendo por tal “[aquello o aquel] Que puede ser herido o recibir lesión, física o moralmente” (RAE, 2019) Más en detalle, la Federación Internacional de Sociedades de la Cruz Roja y de la Media Luna Roja (IFRC, 2017) considera en una publicación reciente que la vulnerabilidad debe entenderse:

[...] como la capacidad disminuida de una persona o un grupo de personas para anticiparse, hacer frente y resistir a los efectos de un peligro natural o causado por la actividad humana, y para recuperarse de los mismos. Es un concepto relativo y dinámico. La vulnerabilidad casi siempre se asocia con la pobreza, pero también son vulnerables las personas que viven en aislamiento, inseguridad e indefensión ante riesgos, traumas o presiones [...] La exposición de las personas a riesgos varía en función de su grupo social, sexo, origen étnico u otra identidad, edad y otros factores. Por otra parte, la vulnerabilidad puede adoptar diferentes formas. (IFRC, 2017) 2 .

En un intento de precisar esta exposición al daño, Ruiz Rivera (2012) sostiene que:

Vulnerabilidad se define siempre en relación con algún tipo de amenaza, sean eventos de origen físico como sequías, terremotos, inundaciones o enfermedades, o amenazas antropogénicas como contaminación, accidentes, hambrunas o pérdida del empleo. (RUIZ RIVERA,2012, p. 63).

En este marco, el autor sitúa la vulnerabilidad en una dimensión social, distinta al “componente físico de la amenaza” (RUIZ RIVERA, 2012, p. 65) y adquiere, en consecuencia, un componente multidimensional que abarca desde las condiciones socioculturales de diferencia y desigualdad hasta la posibilidad de acceso a las políticas públicas de protección, pasando por las estrategias y recursos que permiten desarrollar cierta capacidad de resiliencia ante la afectación o la propia capacidad de respuesta ante avatares imprevistos que actúan como detonadores de vulnerabilidad (BUSSO, 2001).

Este carácter multidimensional comporta una considerable dificultad en la definición precisa de indicadores de exposición, así como de umbrales y gradientes lo suficientemente

\footnotetext{
2 El documento completo en línea puede consultarse en: documento en línea: https://www.ifrc.org/es/introduccion/disaster management/sobre-desastres/que-es-un-desastre/que-es-la-vulnerabilidad.
} 
afinados como para recoger de forma fidedigna la heterogeneidad de las poblaciones expuestas y de los niveles distintos a los que puede experimentarse dicha exposición. En este sentido, es evidente que la vulnerabilidad se ha asociado recurrentemente a la pobreza (SIRVEN, 2007) y a la exclusión social (LAPARRA et al., 2007), lo que ha redundado en una consideración material de la precariedad y, como veremos en el próximo apartado, ha definido situaciones especialmente susceptibles de generar vulnerabilidad y colectivos singularmente propensos a sufrirla.

Por otro lado, Singh, Eghdami y Singh (2014) subrayan el carácter relativo tanto del tipo de evento que pueda dar lugar a la consideración de vulnerable (un caso extremo serían las catástrofes naturales o las tragedias desencadenadas por la acción humana, que afectan a determinadas personas y sectores sociales en mayor medida que a otros) como del nivel de exposición a dicho riesgo. En consecuencia, algunos de estos casos -sobre todo cuando entran en juego factores que adquieren un carácter estructural y actúan más allá del contexto inmediato de necesidad- pueden atraer una mayor atención mediática y publicitaria.

Por consiguiente, si la vulnerabilidad sociocultural aparece como un concepto multidimensional y la delimitación precisa de sus indicadores es una tarea altamente compleja, ¿cómo y bajo qué presupuestos pueden los medios de comunicación abordar estas situaciones? Y ¿De qué modo pueden las campañas de publicidad social contribuir a paliarlas?

\section{Principales temas y focos de interés: El papel de los medios en la aproximación al problema.}

En lo que refiere al rol social de los medios, Elsa González (2015) sostiene que

[...] poseen una responsabilidad de servicio público, ya sean públicos o privados. Y es el periodista quien desarrolla ese papel [...]" (GONZÁLEZ, 2015, p. 5).

Sin embargo, la ejecución de dicho papel no puede ser uniforme puesto que las situaciones que envuelven al servicio prestado pueden variar considerablemente. Así, desde un punto de vista temático, un examen del tratamiento sociomediático y publicitario de la vulnerabilidad sociocultural a la luz de la literatura especializada más reciente nos revela con claridad la 
El papel de la publicidad social em la abordaje de la vulnerabilidad sociocultural. Panorama y reflexiones a propósito del caso español

diversidad de niveles de aproximación al problema. Entre los más recurrentes encontramos los siguientes:

a) tratamiento mediático de colectivos vulnerables, especialmente los menores de edad, que acaban desempeñando un rol central en las informaciones sobre vulnerabilidad que elaboran y difunden los medios de comunicación (MANRIQUE, 2015);

b) campañas publicitarias específicamente dirigidas a menores de edad (CALVERT, 2008; CARTER et al., 2011; HARRIS; KALNOVA, 2018);

c) referencias a los efectos de la publicidad en audiencias infantiles (KIDD; LOXTON, 2018; NORMAN et al., 2018);

d) consecuencias sociales (e.g. marginación, discriminación) de ciertas campañas en determinados colectivos -singularmente jóvenes y adultos jóvenes -(ROSE et al., 2018).

e) riesgo de adicciones a actividades online y a Internet ( $\mathrm{SOH}$ et al., 2018);

f) representaciones de la alteridad en la publicidad social (ARELY DONIS; MARTÍN CASADO, 2017);

g) representaciones de la pobreza en la prensa (CHAUHAN; FOSTER, 2016), posible reproducción de estereotipos en los medios (CLAWSON; TRICE, 2000) y diferencias en el acceso a medios de comunicación debido a factores étnicos o sociales (HSWEN; NASLUND; BICKHAM, 2014);

h) perfiles sociales mediatizados (MAXWELL; COOK, 2014);

i) construcción de mensajes en determinados contextos de vulneración (GARCÍA MARTÍNEZ; FABILA ECHAURI; PÉREZ MORALES, 2011);

j) percepciones sociales sobre las entidades del tercer sector (LARA, 2008).

De dicha prospección se desprende que el epicentro de interés se sitúa en torno a determinados colectivos unánimemente considerados como especialmente vulnerables: refugiados, población situada bajo los umbrales de la pobreza (tal y como se operacionalizan en los indicadores diseñados para calcularla en sus distintas modalidades: absoluta, relativa, multidimensional...) ) $^{3}$ menores (especialmente cuando se utilizan como mano de obra, son refugiados o huérfanos) y víctimas de catástrofes naturales. Todas estas categorías se gradúan en función de tres variables fundamentales: género, franja etaria y adscripción étnica, de modo que la triangulación entre ellas ofrece diferentes niveles relativos de

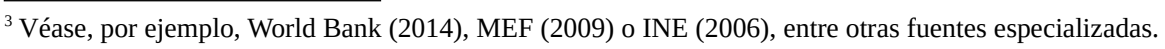


exposición y cuanto mayores son estos, más extensa suele ser la cobertura informativa y el enfoque publicitario en campañas de paliación.

De este modo, las agrupaciones objeto de especial atención mediática corresponden fundamentalmente a ancianos/as (especialmente si viven solos/as), menores, mujeres maltratadas, separadas o solas, y minorías étnicas en situaciones de (o próximas a la) exclusión social. También podría añadirse una cuarta agrupación: personas con diversidad funcional física o psíquica, especialmente cuando se encuentren próximas a alguna de las situaciones anteriormente relacionadas.

Y tanto las informaciones en medios cómo las campañas publicitarias presentan, conforme a los discursos expertos, ámbitos de confluencia bien definidos: (1) necesidades de cuidado, recursos y prestaciones disponibles y necesarias; (2) disponibilidad, consistencia y efectividad de la provisión de servicios mediante políticas públicas; (3) pobreza y condiciones deterioradas de vida; o (4) contextos sociodemográficos específicos de interacción social, normalmente vinculados a entornos propicios a la exclusión o incluso a la marginación social.

Lógicamente, ni los medios en general ni la publicidad en particular permanecen ajenos al contexto sociocultural en el que se desarrollan. En este sentido, debe tenerse en cuenta que la crisis económica iniciada en 2008 con la quiebra financiera de Lehman Brothers en Estados Unidos ha tenido un efecto multiplicador descomunal y ha propulsado el interés general en sus consecuencias. Fijémonos, sólo a título de ejemplo, en las consultas realizadas entre enero de 2004 y julio de 2018 en uno de los buscadores más populares a nivel mundial (Google) sobre el tema "Crisis financiera":

Figura 1 - Consultas sobre el tema "Crisis financiera” en Google. Categorías: "Todas” e "Industria periodística y actualidad" en el conjunto del planeta y en España.

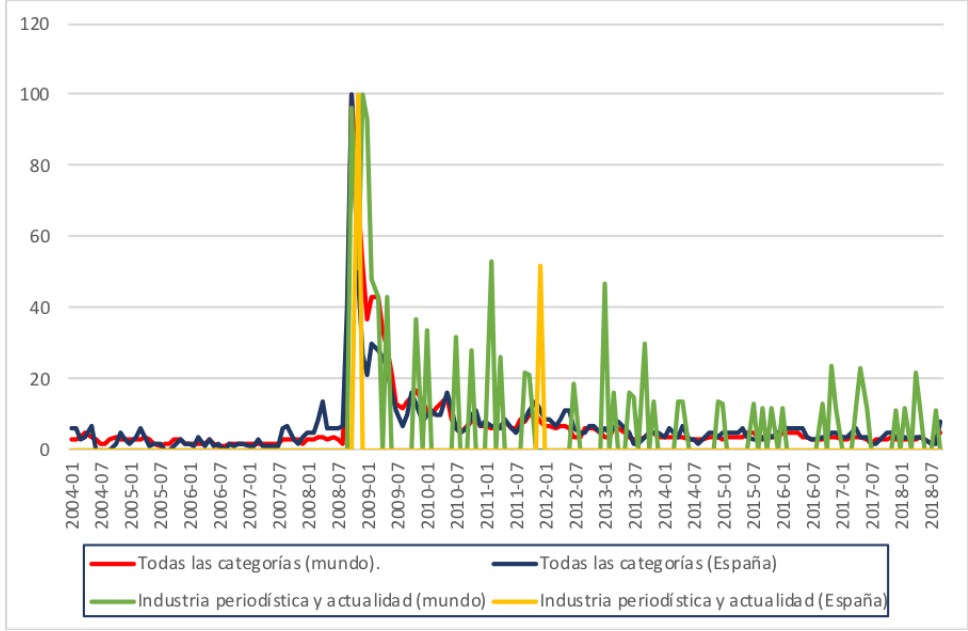

Fuente: Elaboración propia a partir de datos de Google Trends (GOOGLE, 2018). 
Como puede apreciarse, septiembre de 2008 (el día 15 Lehman Brothers hace pública su declaración de quiebra) supone un punto de inflexión, tanto en lo que concierne a las consultas temáticas generales (en todas las categorías del buscador) como a la que específicamente refiere a la industria periodística y de actualidad, y tanto en España como a nivel mundial. El impacto, en lo que refiere a la cobertura informativa a nivel mundial, es manifiestamente visible en la sucesión de picos y valles que han ido trazando las consultas en Internet durante la última década. Todo ello en el marco de un creciente acceso global de usuarios/as a Internet en cualquier parte del mundo (MURPHY; ROSER, 2018).

Con todo, más allá de la atención que han dispensado los medios y de su inestimable labor en el ámbito de la comunicación social (PINAZO, 2003), la centralidad social de la acción comunicativa pone sobre la mesa una dimensión adicional: "[Su] rol central en los procesos de poder simbólico a través de los cuales se definen los temas sociales y se legitiman las soluciones" (BARNETT et al., 2007, p. 296). Este poder se traduce, especialmente en escenarios donde la marginalidad confluye de una u otra manera con las variables de género, edad y adscripción étnica anteriormente descritas en los colectivos generalmente trazados como vulnerables, en: “[...] qué historias se cuentan y cuáles se suprimen, y en cómo las audiencias responden a las nuevas representaciones" (Íd., p. 297).

\section{Estrategias narrativas en la elaboración de campañas sobre pobreza y vulnerabilidad.}

Llegados a este punto, cabe preguntarse ¿cómo se traduce este poder ${ }^{4}$ en la definición concreta de problemas sociales? Un primer acercamiento a los discursos académicos expertos revela que en las campañas de sensibilización acerca de situaciones y contextos de vulnerabilidad el factor emocional juega un papel primordial. Hay un cuidado extraordinario en el lenguaje audiovisual que, además de una ejecución técnica impecable, suele revertir en una potenciación de la conexión empática entre la audiencia y los sujetos representados. Gilboa (2005) o Barnett et al. (2007), entre otros, han puesto de relieve la efectividad de recurrir a narrativas de impacto (sobre todo mediante el uso de imágenes sobrecogedoras) que no únicamente buscan captar la atención del público, sino, sobre todo, incentivar su participación directa o indirecta en la paliación del problema expuesto: es lo que se conoce como "efecto CNN"5.

\footnotetext{
${ }^{4}$ Un poder no exento de críticas respecto a la función y cobertura de los medios en el estallido de la crisis (véase, por ejemplo, GRISOLD; THEINE, 2017) y en cuanto al peso de los mismos en la formación de la opinión pública (CASTELLS, 2008).

${ }^{5}$ Para entender mejor como funciona la dimensión emocional en la publicidad y en sus estrategias creativas véase López Váquez (2007).
} 
Esta huella emocional buscaría dos objetivos complementarios: (a) implicar directamente a amplios sectores sociales en el sustento económico de entidades y organismos sin ánimo de lucro $^{6}$; (b) influir sobre las políticas públicas que puedan implementarse para atenuar en la medida de lo posible las consecuencias sobrevenidas de la vulnerabilidad $-\mathrm{y}$, en la medida de lo posible, también su dimensión estructural-. Esta situación en diversos países, como España, es tanto más acuciante cuanto el efecto paliativo de las transferencias que realiza el sistema de protección social para la reducción de la pobreza es ciertamente limitado y no consigue eliminar el problema ni reducirlo a su mínima expresión (según datos de IDESCAT (2018) correspondientes a 2016, la tasa de riesgo de pobreza antes de transferencias sociales en el conjunto de la Unión Europea era de 25.9\% y tras las mismas desciende hasta el 17.3\%, mientras que en España este diferencial es ligeramente menor -29.5\% vs $22.3 \%$-).

Ante este panorama, Arely Donis y Martín casado (2017) subrayan la centralidad que adquieren el discurso y la representación de los/as vulnerados/as en la publicidad social. Así, los lenguajes audiovisuales incidirán especialmente en aquellos colectivos y situaciones donde intervengan los eslabones más débiles de la cadena; es decir: las agrupaciones a las que me refería páginas atrás: ancianos, menores, minorías en riesgo de exclusión social, etc.

Veamos un par de ejemplos, sólo a título de muestra. El primero de ellos remite al spot "Abuelos solidarios", que forma parte de una campaña de sensibilización de la ONG Educo (2015) orientada a la promoción de becas comedor y que muestra algunas consecuencias de la precariedad familiar, no visible en términos de pobreza extrema, pero sí apreciable en intrahistorias familiares de vulnerabilidad: "Dejar de comer bien para que puedan hacerlo sus hijos o nietos: esta es la realidad de muchos abuelos y abuelas en España" (EDUC0, 2015). En su versión extendida (1'13"), vemos a un personaje femenino caracterizado como una mujer anciana acompañando a un niño y una niña por la calle (Figura 2). Llegan a casa (parece por el contexto que de la mujer) y ésta se pone a cocinar (Figura 3), saliendo al poco tiempo de la cocina hacia el comedor con dos platos (Figura 4) que deposita en la mesa (Figura 5). Tras llamar a comer a los niños, vemos a estos sentados a la mesa ante los platos (Figura 6) mientras preguntan: "Abuela, ¿por qué tú no comes con nosotros?" y ésta responde: "La abuela no tiene hambre, cariño", mientras la vemos, sentada y sola, con un mendrugo de pan entre las manos (Figura 7).

\footnotetext{
${ }^{6}$ Individual giving is always the largest single source of donations, and more than $60 \%$ of U.S. households give to charity [...] This is broadly comparable with countries like the UK, Canada, and Australia [...]. Since such a large proportion of the income for charities is provided by individual donations, how to frame messages proficiently to maximize the responses among public contributors is an important arena in the marketing of NPOs, especially when fundraising competitions among NPOs are fierce. (CHANG; LEE, 2009, p. 2911)
} 
El papel de la publicidad social em la abordaje de la vulnerabilidad sociocultural. Panorama y reflexiones a propósito del caso español

Figura 2 - "Abuelos Solidarios" (Spot Educo)

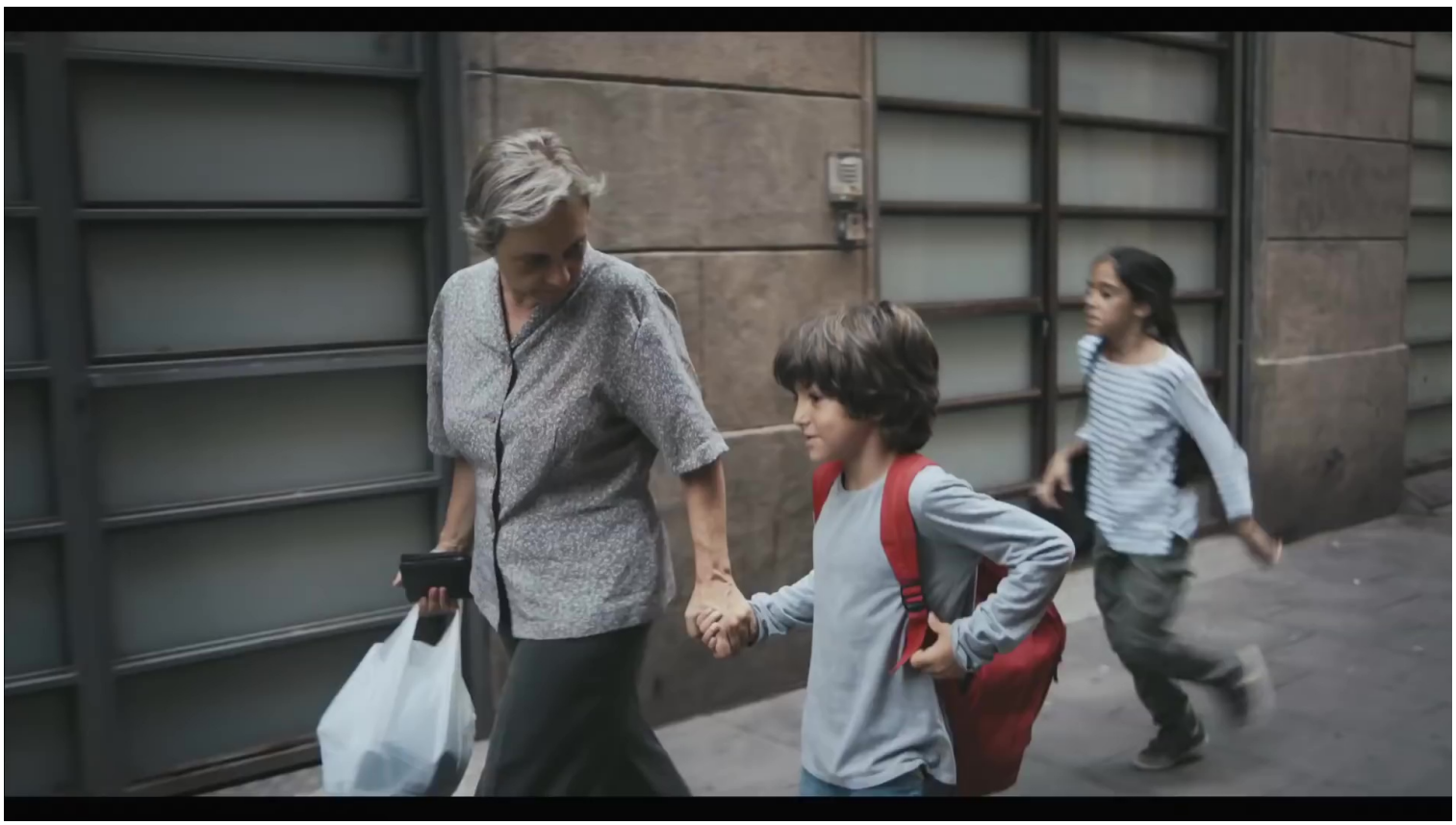

Fuente: Educo (2015).

Figura 3 - "Abuelos Solidarios" (Spot Educo)

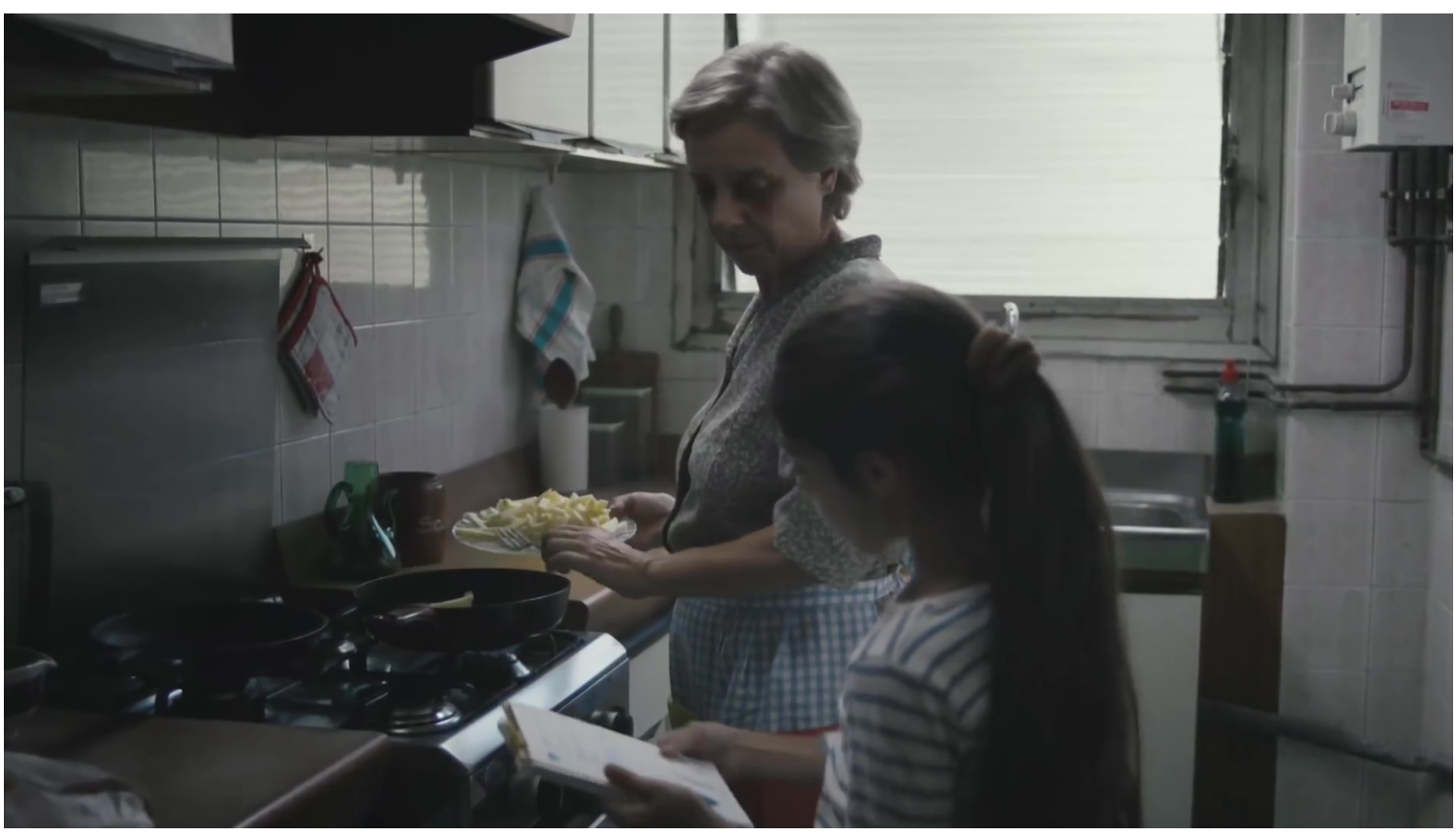

Fuente: Educo (2015). 
El papel de la publicidad social em la abordaje de la vulnerabilidad sociocultural. Panorama y reflexiones a propósito del caso español

\section{Figura 4 - "Abuelos Solidarios" (Spot Educo)}

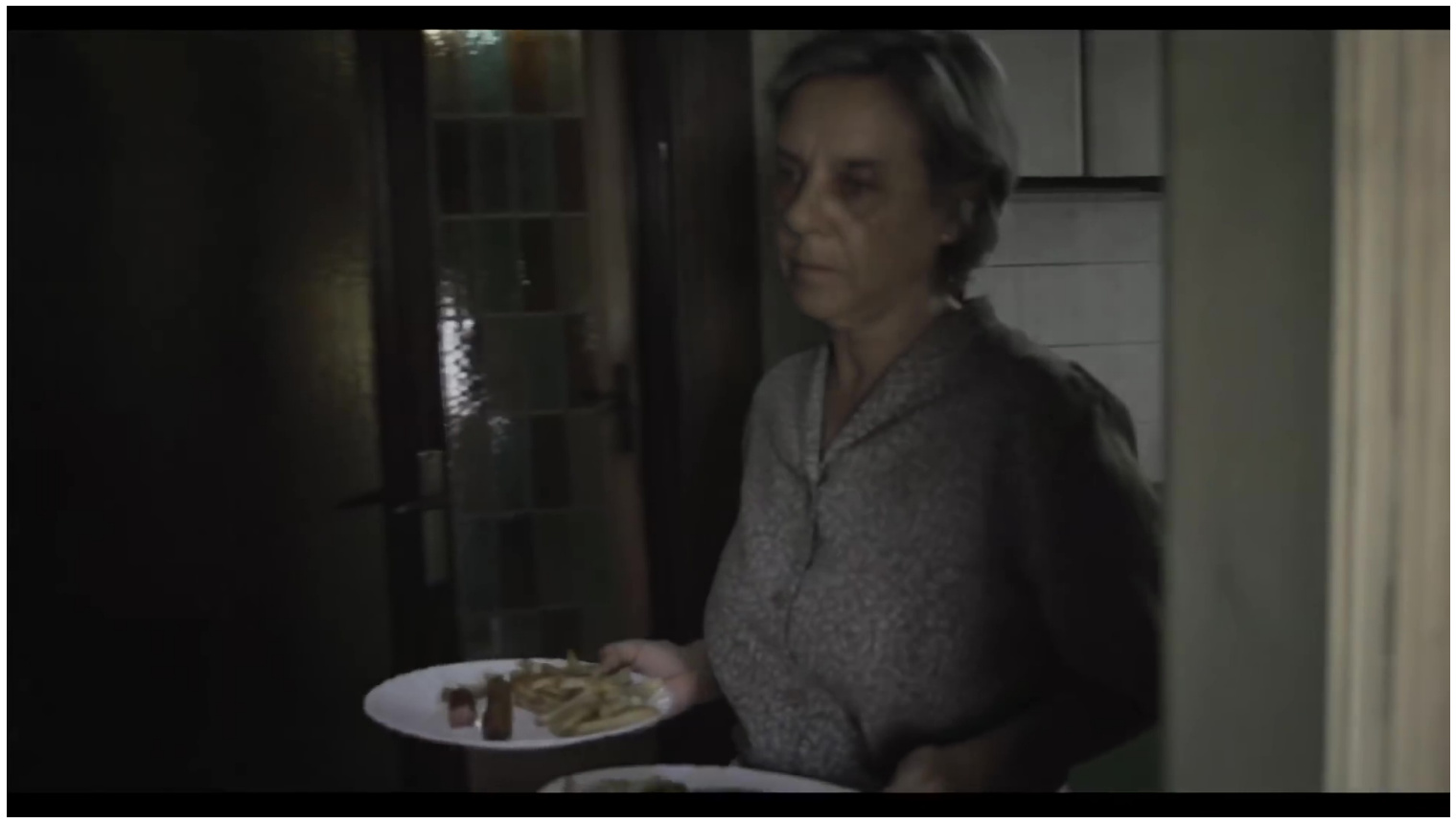

Fuente: Educo (2015).

Figura 5 - "Abuelos Solidarios" (Spot Educo)

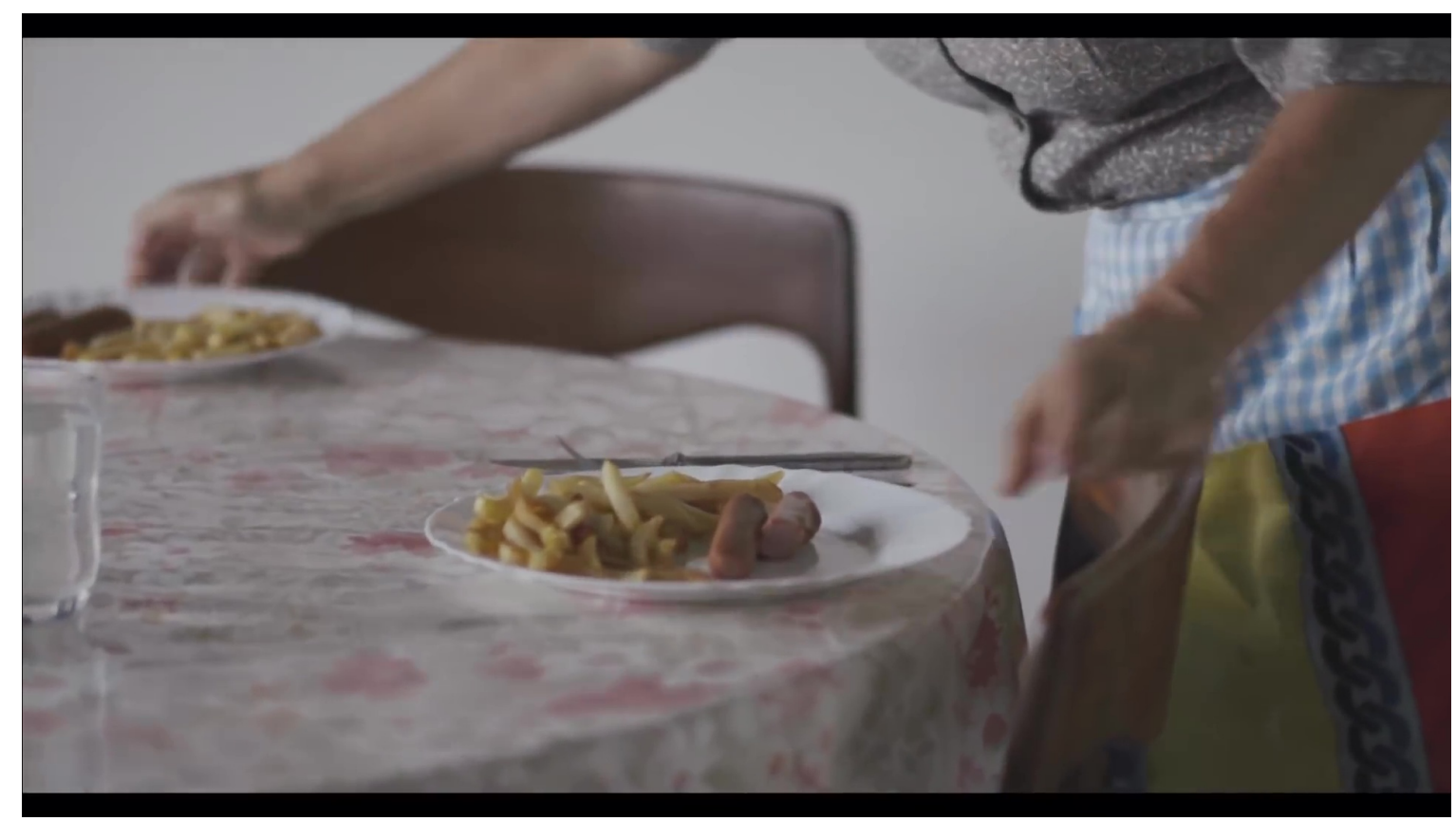

Fuente: Educo (2015). 


\section{Figura 6 - "Abuelos Solidarios" (Spot Educo)}

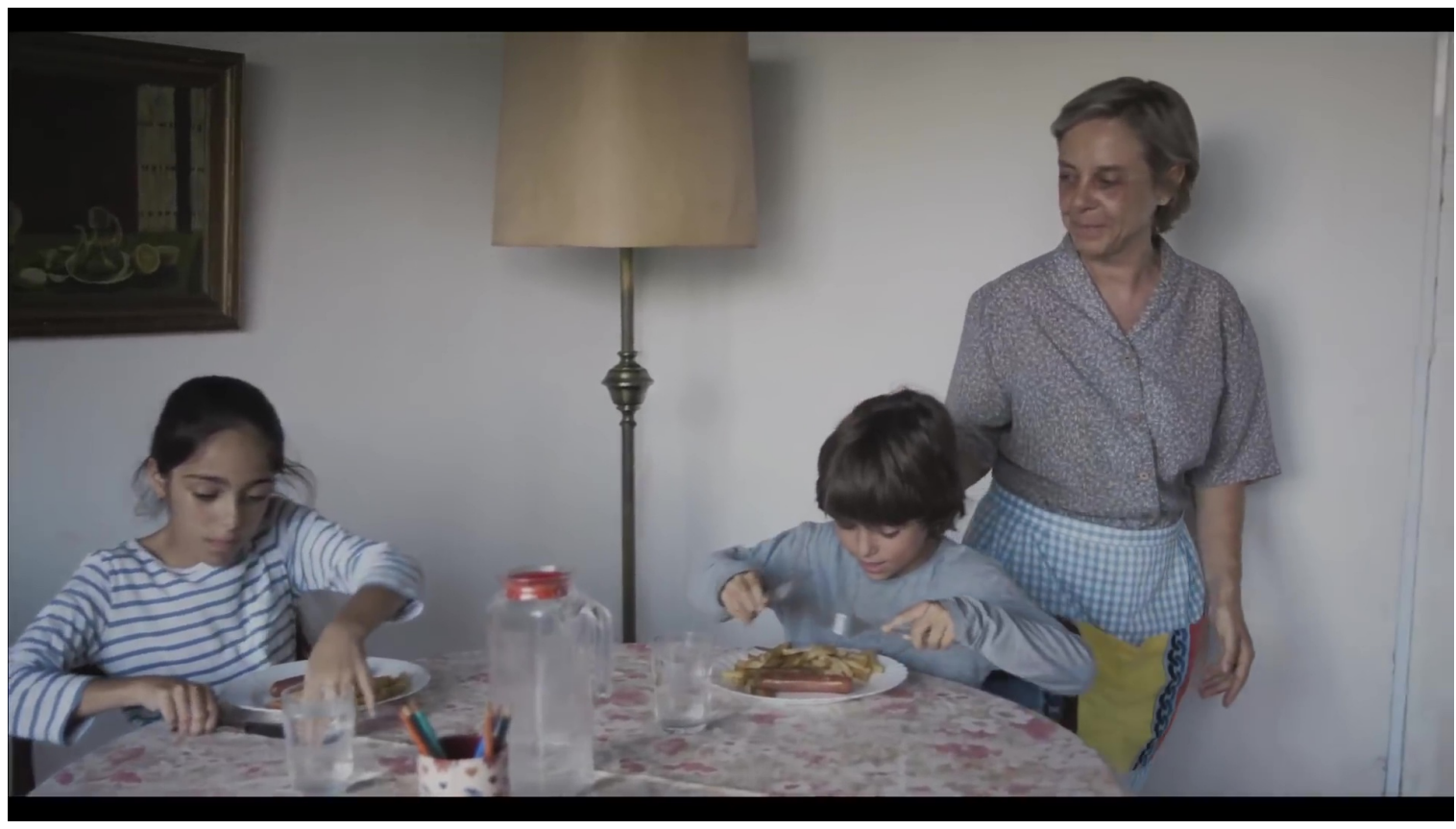

Fuente: Educo (2015).

Figura 7 - "Abuelos Solidarios" (Spot Educo)

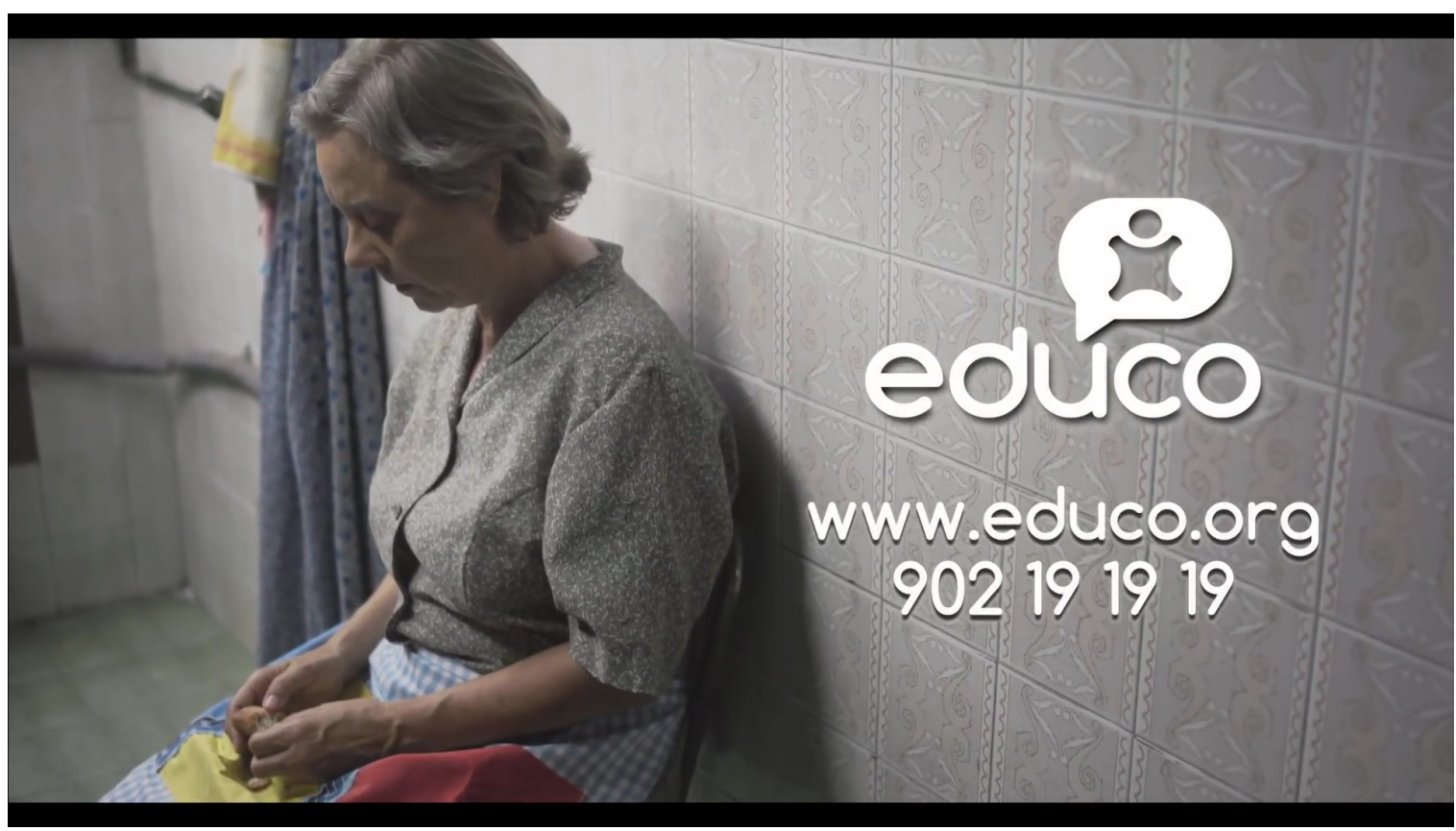

Fuente: Educo (2015).

El segundo forma parte de una campaña de Save the Children en España ( y corresponde al año 2012. En el spot, vemos un travelling de cámara que revela a un menor (podríamos intuir, por el pelo largo, que es una niña) de espaldas mirando a la pared, en una clásica 
El papel de la publicidad social em la abordaje de la vulnerabilidad sociocultural. Panorama y reflexiones a propósito del caso español

postura de castigo (imagen 7). Una voz en off de hombre nos lo confirma mientras progresa el movimiento de cámara: "Estás castigada. Te quedas sin postre, te vas a la cama sin cenar. Se acabó la televisión y la consola, de momento te quedas sin paga [...]". Pocos segundos después, a medida que la cámara se aproxima a la figura cara a la pared en un leve zoom in seguimos oyendo la retahíla de castigos: "[...] te quedas sin reyes, nada de ropa nueva, sin libros, sin calefacción, sin casa, sin ayudas [...]” (imagen 8). Por último, mientras una voz off de mujer explica que "En España más de 2 millones de niños están siendo castigados sin motivo" y pide el apoyo para la ONG en la lucha contra la pobreza infantil (Figura 8).

Figura 8 - "Pobreza infantil en España" (Spot Save the Children)

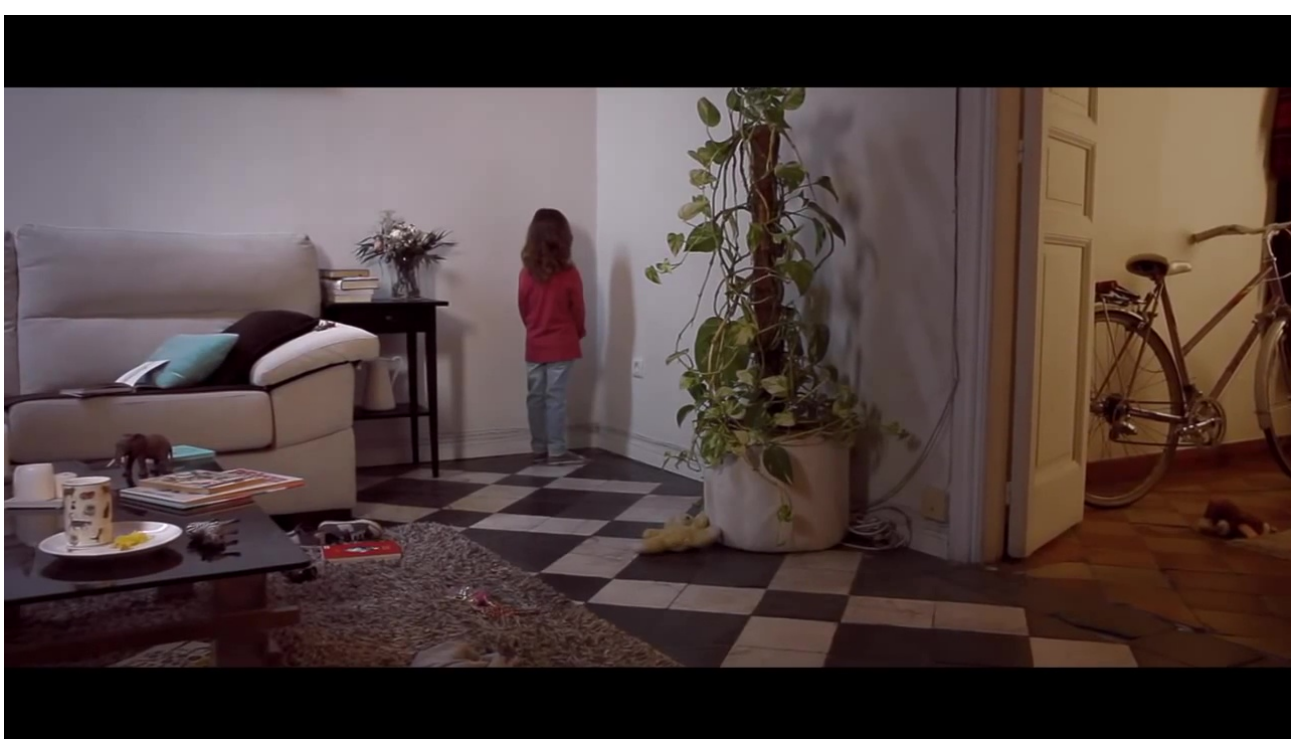

Fuente: Save the children España (2012).

Figura 9 - "Pobreza infantil en España" (Spot Save the Children)

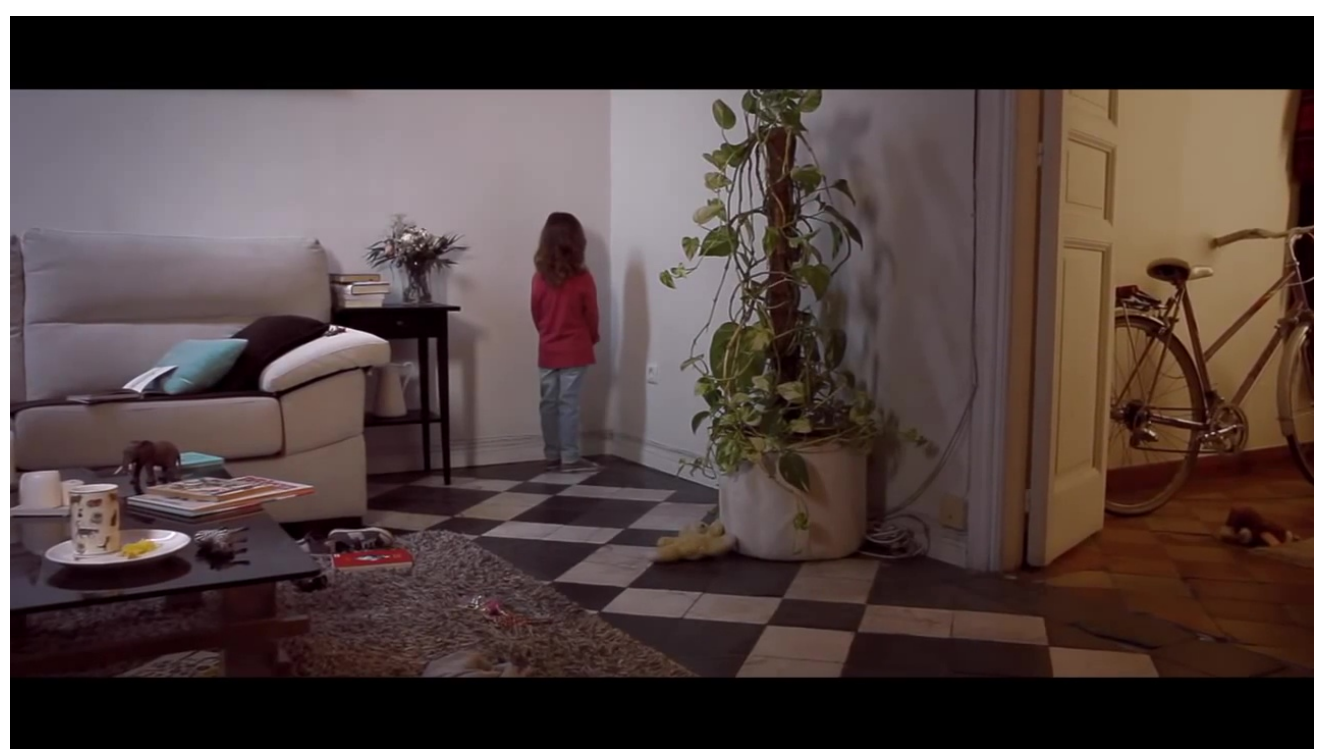

Fuente: Save the children España (2012). 


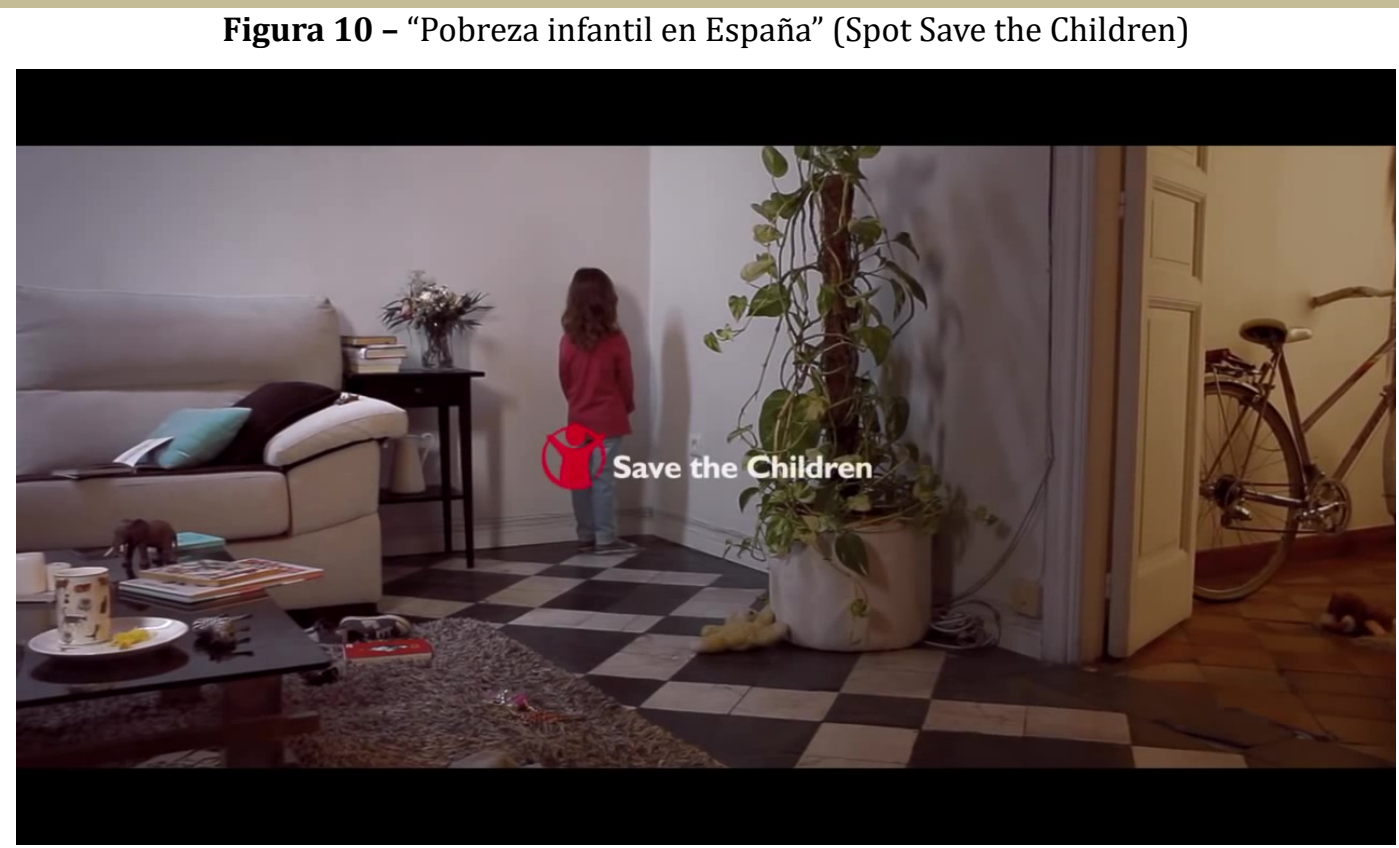

Fuente: Save the children España (2012).

Aunque son únicamente dos ejemplos, que no buscan más representatividad que su condición misma de caso, podemos apreciar en ellos diversas de las características mencionadas anteriormente: el protagonismo de los extremos aparentemente más frágiles de la cadena de vulnerabilidad (ancianos y niños/as), un lenguaje visual perfectamente cuidado, una narrativa que apela a la empatía tanto o más que a la exposición de un problema y la petición explícita de colaboración para combatir los problemas que exponen.

La narración de ambas historias subraya la relevancia del factor emocional en un registro comunicativo que no únicamente pretende informar sobre una situación determinada, sino que promueve abiertamente la intervención social mediante el fomento de una movilización ciudadana que se presume de amplio espectro. En ese sentido, estaríamos ante una comunicación orientada al cambio social en la cual: "La solidaridad es el 'producto' a difundir, lo que provoca en principio un factor positivo de disponibilidad y empatía en la audiencia potencial." (MARFIL, 2013, p. 172). Si en "Abuelos solidarios" son los propios personajes quienes construyen la trama desde su interacción y diálogo, en "Pobreza infantil en España" es el narrador heterodiegético quien se encarga de verbalizar, mediante cuidadas inflexiones en la entonación, aquellos rasgos dramáticos que no son evidentes a primera vista.

Es evidente que la publicidad tiene un propósito persuasivo e incluso lo que ha dado en llamarse campañas sociales o márquetin social (PÉREZ ROMERO, 2004) funcionan en base a la capacidad de movilización e implicación de los targets en los propósitos de la 
campaña, lo que inevitablemente pasa por modificar la conducta de las personas en un sentido tanto reactivo (e.g. en respuesta a una crisis humanitaria en curso) como proactivo (e.g. campañas de prevención). Así, ese poder simbólico al que aludían Barnett et al. (2007) en la definición de grandes temas sociales se encarna en representaciones audiovisuales precisas de supuestos culturales subyacentes a la identificación de colectivos y situaciones y es ahí donde el eco que encuentren estas campañas, así como las consecuencias sociales que puedan comportar sobre diversos sectores de audiencia, cobran un gran relieve.

Es precisamente sobre estas consecuencias que deberíamos aplicar la reflexión de Elsa González (2015) a propósito del carácter de servicio público de medios y campañas, teniendo muy en cuenta las advertencias de Alvarado López, Andrés del Campo y Collado Alonso (2017) acerca de la importancia de orientarse hacia una publicidad más inclusiva que se libere de este tipo de tópicos potencialmente discriminadores:

\begin{abstract}
Una actitud inclusiva de la publicidad enfocaría hacia la diversidad y no hacia la exclusión; hacia la igualdad de derechos, no hacia la homologación de aspectos y situaciones; hacia el reconocimiento de sujetos individuales y colectivos, no hacia su estereotipación; desde un enfoque de participación y corresponsabilidad; y en la senda de la justicia ecosocial y de los derechos fundamentales como fines. (ALVARADO LÓPEZ; ANDRÉS DEL CAMPO; COLLADO ALONSO, 2017, p. 113).
\end{abstract}

Los ejemplos escogidos no inciden en estereotipos sociales o étnicos, especialmente en sus derivaciones negativas. No en vano debemos tener en cuenta, como señala Pérez de Armiño (2006), que “[...] uno puede ser muy vulnerable a un tipo de catástrofe potencial, pero poco a otra, ya que cada una de ellas golpea de forma diferente y pone a prueba aspectos diferentes." (PÉREZ DE ARMIÑO, 2006, p. 1), también en los extremos aparentemente más vulnerables del espectro sociodemográfico. Es primordial, por tanto, tener en consideración las reflexiones de Arely Donis y Martín Casado (2017) a propósito de la importancia que tiene la forma de presentar a los vulnerados, tanto en lo que refiere a lo que de ellos se dice como a las situaciones en las que aparecen. Los casos manejados en este apartado demuestran que una narrativa de alto impacto emocional no requiere la mostración explícita de situaciones degradantes o estigmatizadoras.

Un problema distinto y de gran relevancia estriba en ¿cómo evitar la generalización a todo un colectivo de aquellos rasgos o características que apreciamos en un spot o campaña que recrea una situación determinada con personajes concretos? y ¿de qué modo evitar su extrapolación a contextos distintos al que dan sentido a dicha campaña? Bajo mi punto de 
vista, un modo de prevenir este riesgo estriba en (a) un adecuado conocimiento del entorno sociocultural concreto y (b) un tratamiento apropiado de la vulnerabilidad abordada. En ambas dimensiones los medios de comunicación juegan un papel fundamental en tanto son piezas caudales del engranaje social comunicativo. Atesoran, además, capacidad suficiente para restituir a los afectados su propia voz y establecer el perímetro de riesgo bajo el cual estos colectivos pueden resultar -bajo esas circunstancias particulares- vulnerables. Se avanzaría así hacia una publicidad que, sin perder de vista su enorme importancia comunicativa, pudiera convertirse en operador activo de una mayor y mejor participación de los diversos colectivos de vulnerados/as que visibilicen y den relevancia no sólo a su condición de víctimas, sino también a su papel de agentes potenciales para el cambio.

Para poder cumplir ese propósito debemos, desde las distintas ramas de las Ciencias Sociales y de la Salud, acompañar, ayudar y potenciar la labor de los medios y de la publicidad social. Es este compromiso conjunto de construcción de un conocimiento responsable y socialmente implicado el que adoptamos desde el proyecto de investigación en curso, teniendo muy en cuenta la oportuna advertencia de Lévi-Strauss:

\begin{abstract}
Las ciencias humanas no explican nunca, o muy raras veces, hasta el final, y no predicen sino con una seguridad limitada. Pero de este modo, comprendiendo por cuartos o por mitades, previendo una vez sobre dos o sobre cuatro, no dejan de ser menos aptas, por la íntima solidaridad que instauran entre esas semi-mitades, para otorgar a quienes la practican algo más que está a mitad de camino entre el conocimiento puro y la eficacia; la sabiduría, o por lo menos cierta forma de sabiduría que permite actuar algo menos mal porque se comprende algo mejor, pero sin poder deslindar nunca con exactitud lo que se debe a uno y otro aspecto. $\left(1973^{7}\right.$ apud en GONZÁLEZ ECHEVARRÍA, 1987, p. 215-216).
\end{abstract}

\title{
Conclusiones
}

Lejos de constituirse en meros amplificadores de la realidad, los medios de comunicación, y específicamente el ámbito publicitario, se convierten en operadores de esa misma realidad y devienen herramientas de enorme valor estratégico para actuaciones tanto reactivas como proactivas entre la audiencia. En el ámbito específico de la vulnerabilidad, una prospección documental sobre estudios llevados a cabo en diversos contextos geográficos y políticos revela: (1) la recurrencia de ciertos colectivos y agrupaciones sociales en el eje comunicativo de las campañas de sensibilización, con especial incidencia en los

${ }^{7}$ LÉVI-STRAUSS, C. Antropologie Structurale. París: Plon. 1973. Apud González Echevarría (1987). 
eslabones más frágiles de la cadena; (2) la centralidad de los contextos socioculturales en sus diversas dimensiones (políticas, económicas, demográficas, etc.) para encuadrar y enfocar adecuadamente el fenómeno; (3) el mimo con que se elaboran los lenguajes audiovisuales que sustentan y conforman la narrativa publicitaria y comunicativa y (4) la preferencia por mostrar y acentuar situaciones de impacto para incrementar el efecto que generen entre la audiencia en general y sobre los organismos que pueden incidir en la definición de políticas públicas. Frente a alguna de estas constataciones, se erigen voces cualificadas que reclaman una publicidad más inclusiva mediante la consideración de todos los colectivos implicados, también el de los/as vulnerados/as) como agentes potenciales de transformación y mejora social.

Resta por explorar en futuros estudios de investigación, entre otros ítems relevantes, el peso que juegan los posibles estereotipos sobre los colectivos afectados, así como el imaginario social resultante. En este sentido, debe examinarse con mayor sistematicidad y en contextos socioculturales específicos los posibles efectos que tienen los estereotipos específicamente negativos en la representación de las personas vulnerables, así como el presumible agravamiento que pueden repercutir en la misma los sesgos culturales de género, etnicidad y clase social.

Por último, y no menos importante, convendría también que próximas investigaciones pudiesen abordar, con la profundidad que requiere cada caso particular, la construcción sociomediática de la alteridad, así como su relación con escenarios precisos de pobreza y vulnerabilidad.

\section{Referencias}

VULNERABLE. In: DICCIONARIO de la Real Academia Española. Madrid: Real Academia Española, 2019. Disponível em: http://dle.rae.es/?id=c5dW2by.

ALVARADO LÓPEZ, M. C. ¿Publicidad Social? Usos y abusos de "lo social” en la publicidad. Icono14, [s. l.], v. 7, n. 2, p. 125-151, 2009. Disponível em: https://dialnet.unirioja.es/servlet/articulo?codigo=3195628. Acesso em: 28 set. 2018.

ALVARADO LÓPEZ, M. C.; ANDRÉS DEL CAMPO, S. de; COLLADO ALONSO.. La exclusión social en el marco de la comunicación para el desarrollo y el cambio social. Un análisis del tratamiento de la inclusión social en campañas de servicio público sin ánimo de lucro. Anuario electrónico de estudios en Comunicación Social "Disertaciones", Bogotá, v. 10, n, 1, 2017.

ARELY DONIS, C.; MARTÍN CASADO, T. G. Representation of the Other in social advertising: Analysis of the graphic advertising of NGDOs in social networks. Revista Latina de Comunicacion Social, La Laguna,, v. 72, p. 415-429, 2017. DOI: 10.4185/RLCS, 72-20171172. 
BARNETT, A. et al. Child poverty and government policy: The contesting of symbolic power in newspaper constructions of families in need. Journal of Community and Applied Social Psychology, [s. l.], v. 17, n. 4, p. 296-312, 2007. DOI: https://doi.org/10.1002/casp.933.

BUSSO, G. Vulnerabilidad social: nociones e implicancias de políticas para Latinoamérica a inicios del siglo XXI. In: SEMINARIO INTERNACIONAL SOBRE LAS DIFERENTES EXPRESIONES DE LA VULNERABILIDAD SOCIAL EN AMÉRICA LATINA Y EL CARIBE, 2001, Santiago de Chile. Anais [...].Santiago de Chile: Naciones Unidas - Comisión Económica para América Latina y El Caribe - Cepal, 2001. CALVERT, S. L. Children as consumers: Advertising and marketing. The Future of Children, Nw Jersey,, v. 18, n. 1, p. 205-234, 2008.

\section{CARRASCO, C.; BORDERÍAS, C.; TORNS, T. El trabajo de cuidados. Historia, teoría y} políticas. Madrid: Los Libros de la Catarata, 2011.

CARTER, O. B. J. et al. Children's understanding of the selling versus persuasive intent of junk food advertising: Implications for regulation. Social Science and Medicine, [s. l.], v. 72, n. 6, p. 962-968, 2011.

CASTELLS, Manuel. Comunicación, poder y contrapoder en la sociedad red (I). Los medios y la política. Telos: Cuadernos de comunicación e innovaciónLogroño, n. 74, p. 13-24, 2008.

CHANG, C-T.; LEE, Y-K. Framing Charity Advertising: Influences of Message Framing, Image Valence, and Temporal Framing on a Charitable Appeal. Journal of Applied Social Psychology, [s. l.], v. 39, n. 12, p. 2910-2935, 2009.

CHAUHAN, A.; FOSTER, J. Representations of Poverty in British Newspapers: A Case of "Othering" the Threat? Journal of Community and Applied Social Psychology, [s. l.], v. 24, n. 5, p. 390-405, 2016.

CLAWSON, R. A.; TRICE, R. Poverty as we know it media portrayals of the poor. Public Opinion Quarterly, [s. l.], v. 64, n. 1, p. 53-64, 2000.

DIMAGGIO, P.; GARIP, F.. Network Effects and Social Inequality. Annual Review of Sociology, [s. l.], v. 38, p. 93-118, 2012.

EDUCO. Abuelos Solidarios. España: Educo, 2015. Disponível em: https://www.youtube.com/channel/UCcSjz_zjfOFtW18xAyjhuw.

FUENTES-PELÁEZ, N. et al. The social support in kinship foster care: A way to enhance resilience. Child and Family Social Work, [s. l.] v. 21, n. 4, p. 581-590, 2014.

GARCÍA MARTÍNEZ, V.; FABILA ECHAURI, A.; PÉREZ MORALES, F. de L. Vulnerabilidad social y comunicación, la percepción sobre las funciones de los medios en un desastre. Question, Buenos Aires,, v. 1, n. 31, 2011.

GILBOA, EYTAN. The CNN Effect: The Search for a Communication Theory of International Relations. Political Communication, London,, v. 22, n. 1, p. 27-44, 2005.

GONZALEZ, E. La autorregulación periodística, clave en el tratamiento informativo de la Infancia. In: MANRIQUE, E. (Coord.). La infancia vulnerable en los medios de 
comunicación. Madrid: Aldeas Infantiles SOS de España, 2015. p. 5.

GONZÁLEZ ECHEVARRÍA, A. La construcción teórica en Antropología. Barcelona: Anthropos, 1987.

GOOGLE. Google Trends. 2018. Disponível em: https://trends.google.es/trends/explore? date $=$ all\&geo $=E S \& q=\% 2 F m \% 2 F 088 p 1 q$. Acesso em: 24 set. 2018.

GRISOLD, A.; THEINE, H.. How Come We Know? The Media Coverage of Economic Inequality. International Journal of Communication, Los Angeles, v. 11, p. 4265-4284, 2017.

LÓPEZ-VÁZQUEZ, B. Publicidad emocional. Estrategias creativas. Madrid: ESIC, 2007.

HARRIS, J. L.; KALNOVA, S. S. Food and beverage TV advertising to young children: Measuring exposure and potential impact. Appetite, [s. l.], v. 23, n. 1, p. 49-55, 2018.

HSWEN, Y.; NASLUND, J. A.; BICKHAM, D. S. Differences in media access and use between rural Native American and White children. Rural and Remote Health, [s. l.], v. 14, n. 3, 2014.

IDESCAT. Taxa de risc de pobresa. Per sexe. Barcelona: Institut d'Estadística de Catalunya, 2018. Disponível em: https://www.idescat.cat/indicadors/?id=ue\&n=10122\&t=201600

IFRC. ¿Qué es la vulnerabilidad? - IFRC. Switzerland: IFRC, 2017. Disponível em: $<$ http://www.ifrc.org/es/introduccion/disaster-management/sobre-desastres/que-es-undesastre/que-es-la-vulnerabilidad/>. Acesso em: 23 fev. 2017.

INE. La pobreza y su medición. Presentación de diversos métodos de obtención de medidas de pobreza. Madrid: Instituto Nacional de Estadística, 2006.

INE. Encuesta de Condiciones de Vida (ECV). Año 2015. Madrid: Instituto Nacional de Estadística, 2016.

KIDD, C.; LOXTON, N. J. Junk food advertising moderates the indirect effect of reward sensitivity and food consumption via the urge to eat. Physiology and Behavior, [s. l.], v. 1, n, 188, p. 276-282, 2018.

LA INFANCIA VULNERABLE EN LOS MEDIOS DE COMUNICACIÓN. INFORME 2015. Tu reflexión y sensibilidad, suman. Aldeas Infantiles SOS de España, Madrid, 2015. Disponível em: <http://www.aldeasinfantiles.es/getmedia/f8f077ea-e7e4-477e-9209-

7d983a33e8e2/informe_aldeas_FAPE

LAPARRA, Miguel et al. Crisis y fractura social en Europa: causas y efectos en España. Barcelona: Obra Social La Caixa, 2012 . (Colección Estudios Sociales, n. 35).

LAPARRA, Miguel et al. Exclusión Social Tercer Sector. Madrid: Fundación Luis Vives, número 5, monográfico. 2007.

LARA, M. B. El reto de la comunicación en el tercer sector no lucrativo. Revista española del tercer sector, [s. l.], v. 8, p. 17-37, 2008.

LÉVI-STRAUSS, C. Antropologie Structurale. París: Plon. 1973. 
MANRIQUE, E. (Coord.). La infancia vulnerable en los medios de comunicación. Madrid: Aldeas Infantiles SOS de España, 2015.

MARFIL, R. Interactividad digital y estrategias narrativas en la publicidad audiovisual de Manos Unidas y Unicef. Historia y comunicación social, Madrid, v. 18, N. esp., p. 169-181, 2013.

MATÍAS-SOLANILLA, A. La nueva pobreza y su respuesta desde los sistemas de protección en España. Retos y alternativas del Ingreso Aragonés de Inserción. Análisis de un territorio. Trabajo Social Global-Global Social Work, Granada, v. 5, n. 9, 2015.

MAXWELL, M.; COOK, L. The portrayal of the adopted child in British newspapers and magazines. Vulnerable Children and Youth Studies, London, v. 9, n. 4, p. 318-322, 2014.

MEF. Métodos para medir Pobreza. Perú: MEF, 2009. Disponível em: <https://www.mef.gob.pe/es/mapas-de-pobreza/metodos-para-medir-la-pobreza>. Acesso em: 24 set. 2018.

MEIL, G. Individualización y solidaridad familiar. Barcelona: Obra Social la Caixa, 2011. (Colección Estudios Sociales, $\mathrm{n}^{0}$ 32).

MÉNDEZ, J. Definición y tipos de campaña. 2009. Disponible en https://iman01.files.wordpress.com/2009/11/tipos-de-campanas-publicitarias.pdf, Acceso en: $26 / 11 / 2018$.

MESTRES, S. G. et al. Bulgarian migrants in Spain: Social networks, patterns of transnationality, community dynamics and cultural change in Catalonia (Northeastern Spain). Southeastern Europe, Boston, v. 36, n. 2, p. 208-236, 2012.

MURPHY, J.; ROSER, M. Internet:Our World In Data. Oxford: University of Oxford, 2018..Disponível em: <https://ourworldindata.org/internet>. Acesso em 8 out. 2018.

NAVARRO, V.; CLUA-LOSADA, M.; TUR, M. Introducción. In: NAVARRO, V.; CLUA-LOSADA, M. (eds.). El impacto de la crisis en las familias y en la infancia.Barcelona: Ariel, 2012. p. 1116.

NORMAN, J. et al. Children's self-regulation of eating provides no defense against television and online food marketing. Appetite, [s. l.], v. 1, n. 125, p. 438-444, 2018.

PÉREZ DE ARMIÑO, K. Vulnerabilidad. Barcelona: Icaria, 2006. Disponível em: <http://www.dicc.hegoa.ehu.es/listar/mostrar/228>. Acesso em: 23 fev. 2017.

PÉREZ ROMERO, L. Marketing social: teoría y práctica. Naucalpan: Pearson Educación, 2004.

PINAZO, D. Cambio de actitudes estable. Comunicación social innecesaria. In: BENET, V.; NOS ALDÁS, E. (eds.). La Publicidad en el Tercer Sector. Tendencias y Perspectivas de la Comunicación Solidaria. Barcelona: Icaria, 2003. p. 181-202.

RAE. Vulnerable. Real Academia Española de la Lengua. Disponível em: <https://dle.rae.es/?id=c5dW2by>. Acesso em: 26072019. 
RIVAS, A. M.; JOCILES, M. I. Entre el empoderamiento y la vulnerabilidad: la monoparentalidad como proyecto familiar de las MSPE por reproducción asistida y adopción internacional. Revista de Antropología Social, Madrid, v. 18, p. 127-170, 2009.

RODES LLORET, F.; MONERA OLMOS, C. E.; PASTOR BRAVO, M. del M. Vulnerabilidad infantil: Un enfoque multidisciplinar. Madrid: Díaz de Santos, 2011.

ROSE, S. W. et al. Perceived racial/ethnic discrimination, marketing, and substance use among young adults. Journal of Ethnicity in Substance Abuse, London, v. 9, p. 1-20, 2018.

RUIZ RIVERA, N. La definición y medición de la vulnerabilidad social. Un enfoque normativo. Investigaciones Geográficas, México, n. 77, p. 63-74. 2012.

SAIZ-ECHEZARRETA, V.; ALVARADO, M.-C.; GÓMEZ-LORENZINI, P. Advocacy of trafficking campaigns: A controversy story. Comunicar, Huelva, v. 26, n. 55, 2018.

SAVE THE CHILDREN ESPAÑA. Pobreza infantil en España. España: Save the Children, 2012. Disponível em: https://www.youtube.com/watch?v=nHIUrTuAMLg

SÁNCHEZ-GONZÁLEZ, D.; EGEA-JIMÉNEZ, C. Enfoque de vulnerabilidad social para investigar las desventajas socioambientales: Su aplicación en el estudio de los adultos mayores. Papeles de población, Toluca, v. 17, n. 69, 2011. SÁNCHEZ, A.; SANDÍN, M. P. Joves immigrants i persistència acadèmica: què ens diuen les seves xarxes personals? Temps d'Educació, Barcelona, n. 44, p. 177-190, 2013.

SARASA, S.; LUPPI, F. Crisis económica y pobreza infantil en algunos países de la Unión Europea. In: NAVARRO, V.; CLUA-LOSADA, M (eds.). El impacto de la crisis en las familias y en la infancia.Barcelona: Ariel, 2012. p. 17-55.

SCHRAG, A.; SCHMIDT-TIESZEN, A. Social Support Networks of Single Young Mothers. Child and Adolescent Social Work Journal, Kansas, v. 31, n. 4, p. 315-327, 2014. SEN, A.; BRUNDTLAND, G. H. Romper el ciclo de la pobreza Invertir en la infancia. [s.l: s.n.]. Disponível em: <www.oei.es/historico/inicial/articulos/invertir_infancia.pdf > . Acesso em: 16 fev. 2017.

SINGH, SR; EGHDAMI, MR; SINGH, S. The Concept of Social Vulnerability: A Review from Disasters Perspectives. International Journal of Interdisciplinary and Multidiscipli nary Studies , [s. l.], v. 1, n. 6, p. 71-82, 2014. SIRVEN, N. De la pauvreté à la vulnérabilité: Évolutions conceptuelles et méthodologiques. Mondes en d\{é\}veloppement, [s. l.], v. 35, n. 4, p. 9-24, 2007SOH, P. C. H. et al. Parents vs peers' influence on teenagers' Internet addiction and risky online activities. Telematics and Informatics, [s. l.], v. 35, n. 1, p. 225236, 2018TEZANOS, J. F. et al. En los bordes de la pobreza: las familias vulnerables en contextos de crisis. Madrid: Biblioteca Nueva, 2013.

WORLD BANK. Introduction to poverty analysis (English). Washington,: World Bank Group, 2014..Disponível em <http://documents.worldbank.org/curated/en/775871468331250546/Introduction-topoverty-analysis>. 


\section{O papel da publicidade social no enfrentamento da vulnerabilidade sociocultural. Panorama e reflexões sobre o caso espanhol}

\section{Resumo}

O objetivo deste artigo é refletir, a partir da revisão de literatura internacional relevante sobre o assunto, sobre o papel que a mídia e a publicidade social podem desempenhar na cobertura e no tratamento de situações de vulnerabilidade social, com especial atenção ao caso Espanhol, um dos países europeus mais atingidos pela crise global desencadeada nos Estados Unidos em 2008. Como resultado desta revisão de discursos de especialistas, resumem-se: (a) alguns níveis que frequentemente aparecem como nós centrais da conexão entre publicidade e vulnerabilidade; (b) a delimitação de grupos e coletivos que são particularmente suscetíveis, devido à sua frágil condição, de se tornar um objeto de representação, e (c) algumas áreas de confluência comum no enquadramento do problema. Por conseguinte, a atenção é direcionada para as estratégias narrativas no desenvolvimento de campanhas de conscientização sobre pobreza e vulnerabilidade, combinando informação estatística com a relevância das formas de representação dos sujeitos violados, e recorrendo a dois exemplos concretos de spots publicitários elaborados para este tipo de campanhas na Espanha. Entre as conclusões mais relevantes do texto, destacam-se as recorrências representacionais de determinados grupos, a importância de trabalhar com uma linguagem audiovisual muito cuidadosa, a preferência por focar a atenção narrativa em situações de alto impacto emocional ou o potencial transformador que pode englobar o meio publicitário em ambientes de vulnerabilidade social. Finalmente, áreas relevantes são definidas para serem abordadas em etapas futuras de pesquisa.

\section{Palavras-chave}

Publicidade. Vulnerabilidade social. Estratégias narrativas. Espanha. Linguagem audiovisual.

\section{The role of social advertising in addressing sociocultural vulnerabiblity. Panorama and reflections on the Spanish case.}

The aim of this article is to reflect, from the review of relevant international literature on the subject, about the role that media and social advertising can play in the coverage and treatment of situations of sociocultural vulnerability, with special attention to the Spanish case -one of the European countries more severely hit by the global crisis unleashed in the United States in 2008. 
As a result of this review of expert viewpoints, the following are summarized: (a) some levels that frequently appear as central nodes of the connection between publicity and vulnerability, (b) the delimitation of collectives and groups that are particularly susceptible of becoming an object of representation, due to their vulnerable condition, and (c) some areas of common confluence in the framing of the problem.

Then, attention is directed towards the narrative strategies in the development of awareness campaigns on poverty and vulnerability, combining statistical information with the relevance of the ways of representing the vulnerable subjects, and resorting to two concrete examples of advertising spots prepared in the bosom of this type of campaigns in Spain.

Among the most relevant conclusions of the text, we find the representational recurrences of certain groups, the importance of working with a very accurate audio-visual language, the preference for focusing the narrative attention in situations of high emotional impact, or the transforming potential that can enclose the advertising medium in environments of social vulnerability. Finally, relevant areas are defined to be addressed in future research stages.

\section{Keywords}

Advertising. Social vulnerability. Narrative strategies. Spain. Audio-visual language.

Recebido em 09/10/2018

Aceito em 30/01/2019 